\title{
ON $p$-TH ORDER OF A FUNCTION OF SEVERAL COMPLEX VARIABLES ANALYTIC IN THE UNIT POLYDISC
}

\author{
RATAN KUMAR DUTTA
}

Abstract. This paper is concerned with the study of the maximum modulus and the co-efficients of the power series expansion of a function of several complex variables analytic in the unit polydisc.

Mathematics subject classification (2010): 32A10, 32A15. polydisc.

Keywords and phrases: Analytic function, p-th order, lower p-th order, several complex variables, unit

\section{REFERENCES}

[1] D. BAnerJee, On p-th order of a function analytic in the unit disc, Proc. Nat. Acad. Sci. India 75(A), IV (2005), 249-253.

[2] D. BANERJEe AND R. K. DutTa, Relative order of functions of two complex variables analytic in the unit disc, J. Math. 1 (2008), 37-44.

[3] D. BANERJEe AND R. K. DutTA, On p-th order of a function of two complex variables analytic in the unit polydisc, Proc. Nat. Acad. Sci. India (Section-A) 81, I (2011), 49-58.

[4] R. K. DutTA, On order of a function of several complex variables analytic in the unit polydisc, Journal of Information and Computing Science 6, 2 (2011), 97-108.

[5] O. P. Juneja And G. P. Kapoor, Analytic Functions-Growth Aspects, Pitman Advanced Publishing Program, 1985.

[6] G. P. KAPOOR, On the lower order of functions analytic in the unit disc, Math. Japon. 17 (1972), $49-54$.

[7] G. R. Maclane, Asymptotic Value of Holomorphic Functions, Rice University Studies: Houston, 1963.

[8] D. SATO, On the rate of growth of entire functions of fast growth, Bull. Amer. Math. Soc. 69 (1963), 411-414.

[9] L. R. Sons, Regularity of growth and gaps, J. Math. Anal. Appl. 24 (1968), 296-306. 